\title{
MANTRA PAKASIH DALAM MASYARAKAT BANJAR DI DESA MINA PADI KECAMATAN TAKISUNG KABUPATEN TANAH LAUT
}

\author{
Erni Susilawati, Akhmad HB, dan Irni Cahyani
}

\section{STKIP PGRI Banjarmasin}

Jalan Sultan Adam, Komplek H. Iyus, No. 18 RT.23 Banjarmasin

Kalimantan Selatan. Kode pos 70121,

email: ernisusilawati@ stkipbjm.ac.id,akhmadhb@stkipbjm.ac.id, danirnicahyani@stkipbjm.ac.id

\begin{abstract}
ABSTRAK
Penelitian ini membahas tentang "Mantra Pakasih dalam Masyarakat Banjar di Desa Mina Padi Kecamatan Takisung Kabupaten Tanah Laut". Tujuan penelitian ini adalah: (1) mendeskripsikan struktur mantra pakasih dalam masyarakat Banjar di Desa Mina Padi Kecamatan Takisung Kabupaten Tanah Laut. (2) mendeskripsikan fungsi mantra pakasih dalam masyarakat Banjar di Desa Mina Padi Kecamatan Takisung Kabupaten Tanah Laut. (3) mendeskripsikan makna mantra pakasih dalam masyarakat Banjar di Desa Mina Padi Kecamatan Takisung Kabupaten Tanah Laut.

Pendekatan yang digunakan adalah pendekatan antropologi sastra, jenis penelitian yang digunakan adalah jenis penelitian kualitatif. Sumber data yang digunakan dalam penelitian ini adalah teks mantra pakasih yang berjumlah 11 mantra, yang diperoleh dari hasil wawancara dengan beberapa orang masyarakat Banjar yang bertempat tinggal di Desa Mina Padi Kecamatan Takisung Kabupaten Tanah Laut. Prosedur pengumpulan data yang digunakan dalam penelitian ini adalah teknik observasi, teknik wawancara, dan teknik dokumentasi. Teknik analisis data yang digunakan adalah metode deskriptif analisis.

Berdasarkan hasil penelitian, diperoleh simpulan sebagai berikut: (1) Struktur mantra pakasih dalam masyarakat Banjar di Desa Mina Padi Kecamatan Takisung Kabupaten Tanah Laut menggunakan struktur baris pembuka yang selalu diawali dengan Bismillaahirrahmaaanirrahim. Baris isinya hampir semua ditandai dengan selalu menyebutkan nama orang yang akan yang akan dituju. Sedangkan baris penutupnya berbeda-beda. Ada yang menggunakan lafadz barakatLaa illahailallah Muhammadarasulullah, ada juga yang menggunakan kalimat berkat Allah Taalla dan kalimat Farduku karena Allah Taalla. Walaupun baris penutup yang digunakan tidak sama, namun struktur mantranya tetap sama.(2) Fungsi mantra pakasih dalam masyarakat Banjar di Desa Mina Padi Kecamatan Takisung Kabupaten Tanah Laut, adalah sebagai pengantar atau alat untuk memperkuat permohonan doa kepada Sang Pencipta, baik secara langsung maupun melalui perantara roh-roh leluhur dan makhluk halus yang dipercayai memiliki kekuatan gaib yang dapat digunakan untuk menambah kepercayaan diri Si pengguna, menjadi pusat perhatian di tengah orang banyak, memikat orang yang disukai, dan menjadikan orang sayang dan kasih kepada pembaca mantra. (3) Makna mantra pakasih dalam masyarakat Banjar di Desa Mina Padi Kecamatan Takisung Kabupaten Tanah Laut memiliki makna yang berkenaan dengan hubungan manusia dengan Tuhan, berkenaan dengan hubungan manusia dengan roh-roh leluhur, berkenaan dengan hubungan manusia dengan sesamanya, dan berkenaan dengan manusia dengan dirinya sendiri. Makna yang terkandung dalam mantra-mantra tersebut harus diyakini dan dipercayai oleh orang yang membacakannya agar setiap doa yang dipanjatkan dapat terkabul.
\end{abstract}

Kata Kunci: mantra, pakasih, antropologi sastra 


\section{PENDAHULUAN}

Indonesia memiliki berbagai macam etnik yang unik, budaya yang beraneka ragam, serta beragam jenis bahasa yang digunakan oleh berbagai kelompok masyarakat yang memiliki sistem sosial dan budaya, serta bahasa yang khas. Kekhasan inilah yang terdapat pada karya sastra daerah yang ada pada zaman sekarang maupun yang ada pada masa lalu.

Karya sastra terbagi menjadi dua yaitu sastra tulis dan sastra lisan. Sastra tulis merupakan sastra yang menggunakan media tulisan yang timbul setelah manusia mengenal tulisan. Sastra tulis ini merupakan ciri dari sastra modern, karena bahasa tulisan itu dianggap sebagai perubahan dari masyarakat yang lebih maju. Sedangkan sastra lisan adalah karya yang penyebarannya disampaikan dari mulut ke mulut secara turun temurun (Endaswara, 2013:151). Sastra lisan adalah karya sastra yang tersebar dari mulut ke mulut, karena pada waktu itu orang belum mengenal huruf dan bagian dari suatu kebudayaan yang tumbuh dan berkembang di tengah masyarakat dan diwariskan secara turun temurun secara lisan. Sastra lisan juga memiliki fungsi sebagai cerminan sikap pandang dan angan-angan kelompok, alat pendidikan anak, alat pengesahan pranata dan kebudayaan, serta alat pemeliharaan norma-norma masyarakat.

Karya sastra lisan yang ada di Kalimantan Selatan sangatlah beragam, salah satu diantaranya adalah sastra Banjar genre lama yang bercorak puisi misalnya saja seperti madihin, mantra, pantun, peribahasa, tamsil, dan syair. Karya sastra lisan berupa mantra banyak digunakan oleh orang-orang yang ada di Kalimantan Selatan, dikarenakan mantra diyakini sebagai bentuk sastra lisan yang paling tua yang mengandung kekuatan gaib dan kesaktian. Salah satu jenis mantranya yaitu mantra pakasih.

Mantra pakasih merupakan mantra Banjar yang biasanya digunakan oleh sebagian masyarakat untuk mengguna-gunai lawan jenis agar bertambah tunduk dan kasih kepada penggunanya. Ciri dari mantrapakasihterlihat dari kosakatanya yang berisi permohonan agar lawan jenis Si pengguna mantra yang dituju menjadi semakin bertambah kasih.

Selain fungsinya yang sangat diyakini, terdapat pula struktur dan maknanya yang sangat menarik untuk dikaji. Jenis karya sastra lisan Banjar genre lama bercorak puisi yang mana terdapat struktur berupa baris pembuka, baris isi, dan baris penutup. Tiga hal tersebut yang membuat peneliti mengkaji mantra pakasih dengan analisis struktur, fungsi, dan maknanya.

Seiring dengan kemajuan zaman saat ini, tradisi-tradisi itu sudah mulai berkurang, khususnya yang mengkaji Mantra Pakasih, karena dirasa sangat menyulitkan. Prosesnya hanya bisa 
dilakukan oleh orang-orang tertentu saja, jarang sekali ditemukan generasi penerus yang mewarisinya, dan dikarenakan kemajuan teknologi yang berkembang saat ini membuat sebagian masyarakat yang begitu percaya secara penuh masih mempertahankan dan adapula sebagian masyarakat lainnya secara langsung atau tidak langsung menolak kehadiran mantra dengan pertimbangan bahwa menerima mantra berarti melakukan perbuatan syirik. Oleh karena itu, adat istiadat atau tradisi yang sudah mulai berkurang dan rentan untuk hilang ini perlu untuk dikaji dan diadakan penelitian dan dokumentasi budaya.

Mantra pakasihini umumnya lebih banyak digunakan oleh masyarakat Banjar, karena kepercayaan masyarakat Banjar terhadap hal yang berbau-bau magis tersebut sangatlah kuat. Akan tetapi, mantra saat ini sudah jarang sekali dipakai ataupun dipergunakan oleh masyarakat banjar masa sekarang. Oleh sebab itu, peneliti melakukan penelitian tentang mantra yang di dalamnya terdapat struktur, fungsi, dan maknanya yang memang tidak mudah dimengerti oleh masyarakat pada umumnya. Mantra terbagi menjadi dua, ada yang sifatnya positif dan ada juga yang negatif tergantung bagaimana seorang pemakai mantra menggunakannya. Akan tetapi, pemakaian mantra tersebut tidak sembarang pakai, karena harus dengan keyakinanlah mantra tersebut akan dikatakan berhasil. Dalam hal ini, sebuah mantra diyakini dapat menaklukan seseorang yang dituju. Karena mantra tersebut bersifat magis.

\section{METODE}

Pendekatan yang digunakan dalam penelitian yang berjudul Mantra Pakasih dalam Masyarakat Banjar di Desa Mina Padi Kecamatan Takisung Kabupaten Tanah Laut, membahas tentang gambaran-gambaran manusia menonjolkan kebudayaannya melalui pendekatan antropologi. (Ratna, 2015:63-65) mengatakan pendekatan Antropologi adalah ilmu pengetahuan mengenai manusia dalam masyarakat. Lahirnya antropologis, didasarkan atas kenyataan, pertama, adanya hubungan antara ilmu antropologi dengan bahasa. Kedua, dikaitkan dengan tradisi lisan maupun tulisan, baik antropologi maupun sastra sama-sama mempermasalahkannya sebagai objek yang penting. Oleh karena itu, dalam penelitian sastra lisan, mitos, dan sistem religi, sering di antara kedua pendekatan terjadi tumpang tindih.

Antropologi yang dimaksud disini lebih memusatkan pada penduduk yang merupakan masyarakat tunggal, tunggal dalam artian disini merupakan masyarakat kesatuan yang tinggal di daerah yang sama. Dalam kaitannya dengan sastra, antropologi kebudayaan pun dibedakan menjadi dua bidang, yaitu antropologi dengan objek verbal dan nonverbal, pendekatan antropologi sastra 
lebih banyak berkaitan dengan objek verbal.Jadi secara umum, antropologi sastra dapat diartikan sebagai kajian terhadap pengaruh timbal balik antara sastra dengan kebudayaan.Berdasarkan itulah telaah yang digunakan terfokus pada nilai-nilai budaya kemasyarakatan yang terdapat dalam mantra pakasih, yang mempersoalkan segi-segi yang menunjang pembinaan dan tata kehidupan yang terdapat pada mantra masyarakat Banjar. Jadi, pendekatan antropologis ini menurut peneliti tepat digunakan dalam penelitian sastra lisan Banjar yang berupa mantra pakasih.

Jenis penelitian yang digunakan dalam penelitian ini adalah penelitian kualitatif, karena penelitian kualitatif tidak berupa angka, namun terurai dalam bentuk kata-kata sesuai dengan apa yang didapat dalam penelitian di lapangan. Sependapat dengan Mc Millan dan Schumacher (Syamsuddin dan Damaianti, 2015:73-74), yang menyatakan bahwa penelitian kualitatif merupakan suatu pendekatan yang juga disebut pendekatan investigasi, karena biasanya peneliti mengumpulkan data dengan cara bertatap muka langsung dan berinteraksi dengan orang-orang di tempat penelitian. Dalam penelitian kualitatif, peneliti dilibatkan dalam fenomena yang sedang dipelajari. Peneliti juga mengasumsikan fungsi interaksi sosial dengan cara pendekatan interaktif netral-tradisional dan interaksi aktif. Peneliti mengumpulkan data, menyusun data, mengklasifikasikan data, dan melaporkan hasil penelitian secara apa adanya sesuai dengan data yang diperoleh dalam penelitian.

Penelitian ini bertujuan untuk mendeskripsikan struktur, fungsi, dan makna mantra pakasih dalam masyarakat Banjar di Desa Mina Padi Kecamatan Takisung Kabupaten Tanah Laut dengan Telaah Antropologi Sastra. Untuk mewujudkan tujuan penelitian, maka penelitian ini dilaksanakan dengan menerapkan jenis penelitian kualitatif dan pendekatan antropologis.

\title{
HASIL DAN PEMBAHASAN
}

Struktur MantraPakasih dalam Masyarakat Banjar di Desa Mina Padi Kecamatan Takisung Kabupaten Tanah Laut

Struktur mantra merupakan susunan dari mantra pakasih yang berupa kalimat pembuka, isi, dan kalimat penutup.

\section{Mantra Kata Siti Fatimah Zahaura}

\author{
Bismillaahirrahmaaanirrahim \\ Nur sah, Nur siah \\ Aku membasuh ceramin Allah \\ Aku membasuh ceramin Baginda Rasulullah \\ Oh, Fatimah Zahaura \\ Sempurnakanlah rupaku
}


Takaulas, takauning asih

Takaulas, takauning sayang

Tunduk, kasih, sayang Si ... (nama orang) lawan aku

Berakat aku memakai doa Laa Illaha Illallah Muhammadarrasulullah

Mantra Kata Siti Fatimah Zahaura memiliki struktur baris pembuka, isi dan penutup. Pada baris pembukanya diawali dengan kalimat pembuka pendek yaitu Bismillahirrahmanirrahiim. Baris isinya terlihat pada kutipan Nur sah Nur siah, Aku membasuh ceramin Allah, Aku membasuh ceramin Baginda Rasulullah, Oh Fatimah Zahaura, Sempurnakanlah rupaku, Takaulas takauning asih, Takaulas takauning sayang, Tunduk kasih sayang Si ... (nama orang) lawan aku.

Baris penutupnya di akhiri dengan kalimat Laa Illaha Illallah Muhammadarrasulullah.

\section{Mantra Kata Tadung Beranakkan}

Bismillaahirrahmaaanirrahim

Kulya sinnadri

Matahari memancar di mukaku

Halilintar membelahkan suaraku

Tadung berkokok atas umbun-umbunanku

Takaulas, takauning asih

Takaulas, takauning sayang

Tunduk, kasih, sayang Si ... (nama orang) lawan aku

Berakat aku memakai doa Laa Illaha Illallah Muhammadarrasulullah

Mantra Kata Tadung Beranakkan mempunyai struktur baris pembuka, isi dan penutup. Pada baris pembukanya diawali dengan kalimat pembuka pendek yaitu Bismillahirrahmanirrahiim. Baris isi seperti yang terlihat pada kutipan Matahari memancar di mukaku, Halilintar membelahkan suaraku, Tadung berkokok atas umbun-umbunanku, Takaulas takauning asih, Takaulas takauning sayang,Tunduk kasih, sayang Si ... (nama orang) lawan aku. Baris penutupnya diakhiri dengan kalimat Laa Illaha Illallah Muhammadarrasulullah.

\section{Mantra Pengunci Diri}

Bismillaahirrahmaaanirrahim

Kunci Allah

Kunci Muhammad

Kunci Baginda Rasulullah

Muhammad menguncikannya

Tertutup, terkunci hati Si ... (nama orang)

Tiada berkehendak kepada orang lain

Selain pada diriku

Berakat Laa Illaha Illallah Muhammadarrasulullah 
Mantra Pengunci Diri berstruktur baris pembuka, isi dan penutup. Pada baris pembukanya diawali dengan kalimat pembuka pendek yaitu Bismillahirrahmanirrahiim. Baris isinya terlihat pada kutipan Kunci Allah, Kunci Muhammad, Kunci Baginda Rasulullah, Muhammad menguncikannya, Tertutup, terkunci hati Si ... (nama orang) Tiada berkehendak kepada orang lain, Selain pada diriku. Baris penutupnya diakhiri dengan kalimat Laa Illaha Illallah Muhammadarrasulullah.

\title{
4. Mantra Penunduk Kekasih Hati
}

\author{
Bismillaahirrahmaaanirrahim \\ Unduk-unduk piradah patah \\ Aku berdiri di awan-awan \\ Inya tunduk tiada berkata \\ Benar berani tidak berlawan \\ Menurut semua perkataanku \\ Berkat mengatakan doa Laa Illaha Illallah Muhammadarrasulullah
}

Mantra Penunduk Kekasih Hati memiliki struktur baris pembuka, isi dan penutup. Pada baris pembukanya diawali dengan kalimat pembuka pendek yaitu Bismillahirrahmanirrahiim. Baris isi seperti yang terlihat pada kutipan Unduk-unduk piradah patah, Aku berdiri di awan-awan, Inya tunduk tiada berkata, Benar berani tidak berlawan, Menurut semua perkataanku. Baris penutupnya diakhiri dengan kalimat Laa Illaha Illallah Muhammadarrasulullah.

\section{Mantra Mandi Pemikat Lawan Jenis}

Bismillaahirrahmaaanirrahim

Allahhumma sholli alla Muhammad

Ampunnya kata Fatimah jua nang menyambutnya

Karim Menimba air di api

Karing tiada ada lagi

Ini benama kambang sekuntum para wali

Inya kepingsan, inya kepati

Singgah memungut si laki-laki

Berakat mengatakan doa Laa Illaha Illallah Muhammadarrasulullah

Mantra Mandi Pemikat Lawan Jenis berstruktur baris pembuka, isi dan penutup. Pada baris pembukanya diawali dengan kalimat pembuka pendek yaitu Bismillahirrahmanirrahiim dan Allahhumma sholli alla Muhammad berupa salam pembuka. Baris isi seperti yang terlihat pada kutipan Ampunnya kata Fatimah jua nang menyambutnya, Karim Menimba air di api,Karing tiada ada lagi, Ini bernama kambang sekuntum para wali, Inya kepingsan, Inya kepati, singgah 
memungut Si laki-laki. Baris penutupnya diakhiri dengan kalimat Laa Illaha Illallah Muhammadarrasulullah.

\title{
6. Mantra Pupur Pakasih
}

\author{
Bismillaahirrahmaaanirrahim \\ Pupurku Si pupur beras \\ Ditampi di ujung limbukut \\ Cahayaku seperti emas \\ Cahayaku seperti Nabilah Yusuf \\ Terkulas, terkening ngasih \\ Terkening gila-gilalah Si ... (nama orang) kepadaku \\ Berkat mengatakan doa Laa Illaha Illallah Muhammadarrasulullah
}

Mantra Pupur Pakasih memiliki struktur baris pembuka, isi dan penutup. Pada baris pembukanya diawali dengan kalimat pembuka pendek yaitu Bismillahirrahmanirrahiim. Baris isinya seperti yang terlihat pada kutipan Pupurku Si pupur beras, Ditampi di ujung limbukut, Cahayaku seperti emas, Cahayaku seperti Nabilah Yusuf, Terkulas terkening ngasih, Tergila-gilalah Si ... (nama orang) kepadaku. Baris penutupnya diakhiri dengan kalimat Laa Illaha Illallah Muhammadarrasulullah.

\section{Mantra Minyak}

Bismillaahirrahmaaanirrahim

Burung terabang disengkanya aku

Ayam berkokok disangkanya aku

Angin bertiup disangkanya aku

Orang berjalan disangkanya aku

Tunduk, kasih, sayangnya Si ... (nama orang) lawan aku

Berkat Allah Taalla

Mantra Minyak mempunyai struktur baris pembuka, isi dan penutup. Pada baris pembukanya diawali dengan kalimat pembuka pendek yaitu Bismillahirrahmanirrahiim. Baris isinya seperti yang terlihat pada kutipan Burung terbang disangkanya aku, Ayam berkokok disangkanya aku, Angin bertiup disangkanya aku, Orang berjalan disangkanya aku, Tunduk kasih sayangnya Si ... (nama orang) lawan aku. Baris penutupnya diakhiri dengan kalimat penutup yaitu Berkat Allah Taalla. 


\title{
8. Mantra Kata Yusuf
}

\author{
Bismillaahirrahmaaanirrahim \\ Bapakku Adam \\ Ibuku Siti Hawa \\ Rupaku yusuf \\ Tunduk maras \\ Gila hati Si ... (nama orang) \\ Memandang aku \\ Farduku karena Allah Taalla
}

Mantra Kata Yusuf memiliki struktur baris pembuka, isi dan penutup. Pada baris pembukanya diawali dengan kalimat pembuka pendek yaitu Bismillahirrahmanirrahiim. Baris isinya seperti yang terlihat pada kutipan Bapakku Adam, Ibuku Siti Hawa, Rupaku yusuf, Tunduk maras, Gila hati Si ... (nama orang) memandang aku. Baris penutupnya diakhiri dengan kalimat penutup yaitu Farduku karena Allah Taalla.

\section{Fungsi MantraPakasih dalam Masyarakat Banjar di Desa Mina Padi Kecamatan Takisung Kabupaten Tanah Laut}

Fungsi mantra merupakan suatu kegunaan dalam melakukan suatu hal yang dipenuhi dengan keyakinan yang kuat. Fungsi mantra sebagai alat/media komunikasi penutur kepada Makhluk gaib atau Roh leluhur yang dipercayai dapat membantu dalam memenuhi keinginannya.

\section{Mantra Kata Siti Fatimah Zahaura}

\section{Bismillaahirrahmaaanirrahim}

Nur sah, Nur siah

Aku membasuh ceramin Allah

Aku membasuh ceramin Baginda Rasulullah

Oh, Fatimah Zahaura

Sempurnakanlah rupaku

Takaulas, takauning asih

Takaulas, takauning sayang

Tunduk, kasih, sayang Si ... (nama orang) lawan aku

Berakat aku memakai doa Laa Illaha Illallah Muhammadarrasulullah

Kutipan mantra tersebut menggambarkan fungsi mantra yang dibacakan oleh penggunanya untuk menambah kepercayaan diri Si penutur, dengan meminta agar menyempurnakan rupanya sehingga dapat memikat hati orang yang disukai menjadi tunduk dan semakin bertambah kasih kepadanya. 


\section{Mantra Kata Tadung Beranakan}

Bismillaahirrahmaaanirrahim

Kulya sinnadri

Matahari memancar di mukaku

Halilintar membelahkan suaraku

Tadung berkokok atas umbun-umbunanku

Takaulas, takauning asih

Takaulas, takauning sayang

Tunduk, kasih, sayang Si ... (nama orang) lawan aku

Berakat aku memakai doa Laa Illaha Illallah Muhammadarrasulullah

Kutipan mantra berikut menggambarkan fungsi mantra yang dibacakan oleh penggunanya untuk menambah kepercayaan diri Si pengguna mantra, menjadi pusat perhatian di tengah orang banyak dengan meminta agar disempurnakan rupa dan suaranya sehingga terdengar merdu, dan dapat membuat orang yang disukai menjadi tunduk dan semakin bertambah kasih kepadanya.

\section{Mantra Pengunci Diri}

Bismillaahirrahmaaanirrahim

Kunci Allah

Kunci Muhammad

Kunci Baginda Rasulullah

Muhammad menguncikannya

Tertutup, terkunci hati Si ... (nama orang)

Tiada berkehendak kepada orang lain

Selain pada diriku

Berakat Laa Illaha Illallah Muhammadarrasulullah

Kutipan mantra di atas menjelaskan fungsi mantranya sebagai sarana magis untuk mengguna-gunai orang yang dituju dengan menutup dan mengunci hati orang tersebut, agar tidak memiliki rasa suka dan tertarik terhadap orang lain selain kepada pengguna mantra tersebut.

\section{Mantra Penunduk Kekasih Hati}

Bismillaahirrahmaaanirrahim

Unduk-unduk piradah patah

Aku berdiri di awan-awan

Inya tunduk tiada berkata

Benar, berani tidak berlawan

Menurut semua perkataanku

Berkat mengatakan doa Laa Illaha Illallah Muhammadarrasulullah 
Kutipan mantra tersebut memberikan gambaran mengenai fungsi mantra sebagai sarana magis untuk mengguna-gunai orang yang dituju, agar apabila mantra tersebut dibacakan dapat membuat orang yang dituju menjadi tunduk dan kasih kepada penggunanya.

\section{Mantra Mandi Pemikat Lawan Jenis}

\section{Bismillaahirrahmaaanirrahim}

Allahhumma sholli alla Muhammad

Ampunnya kata Fatimah jua nang menyambutnya

Karim Menimba air di api

Karing tiada ada lagi

Ini benama kambang sekuntum para wali

Inya kepingsan, inya kepati

Singgah memungut si laki-laki

Berakat mengatakan doa Laa Illaha Illallah Muhammadarrasulullah

Kutipan mantra di atas menggambarkan fungsi mantra yang dibacakan oleh penggunanya meminta agar orang yang dituju tersebut menjadi terpikat apabila melihat Si pengguna mantra tersebut. Sehingga orang yang dituju tersebut menjadi sayang dan kasih kepada penggunanya.

\section{Mantra Pupur Pakasih}

Bismillaahirrahmaaanirrahim

Pupurku Si pupur beras

Ditampi di ujung limbukut

Cahayaku seperti emas

Cahayaku seperti Nabilah Yusuf

Terkulas, terkening ngasih

Terkening gila-gilalah Si ... (nama orang) kepadaku

Berkat mengatakan doa Laa Illaha Illallah Muhammadarrasulullah

Kutipan mantra berikut memberikan gambaran fungsi mantra yang dibacakan oleh Si pengguna, meminta untuk menyempurnakan rupanya agar menambah kepercayaan dirinya, sehingga menjadi pusat perhatian di tengah orang banyak, dan dapat membuat orang yang disukai menjadi semakin bertambah kasih dan tergila-gila kepada penggunanya.

\section{Mantra Minyak}

Bismillaahirrahmaaanirrahim

Burung terbang disengkanya aku

Ayam berkokok disangkanya aku

Angin bertiup disangkanya aku

Orang berjalan disangkanya aku 
Tunduk, kasih, sayangnya Si ... (nama orang) lawan aku Berkat Allah Taalla

Kutipan mantra di atas memberikan gambaran fungsi mantra sebagai sarana magis untuk mengguna-gunai orang yang dituju agar apabila mantranya dibacakan dapat membuat orang tersebut tidak bisa melupakan penggunanya (selalu ingat) dan tunduk kasih kepada penggunanya.

\section{Mantra Mandi Yusuf}

\section{Bismillaahirrahmaaanirrahim \\ Bapakku Adam \\ Ibuku Siti Hawa \\ Rupaku yusuf \\ Tunduk maras \\ Gila hati Si ... (nama orang) \\ Memandang aku \\ Farduku karena Allah Taalla}

Kutipan mantra berikut memberikan gambaran fungsi mantra agar orang yang menggunakan mantra tersebut terlihat sempurna oleh semua orang. Mantra tersebut bisa juga digunakan untuk mengguna-gunai orang yang akan dituju saja agar orang tersebut menjadi tunduk dan tergila-gila apabila melihat Si Pengguna mantra tersebut.

\section{Makna Mantra Pakasih dalam Masyarakat Banjar di Desa Mina Padi Kecamatan}

\section{Takisung Kabupaten Tanah Laut}

Makna mantra adalah sebuah arti atau maksud yang benar dan dipercayai dalam sebuah mantra bisa berupa kata-kata yang mempunyai arti atau bahkan kata-kata yang tak berarti, tetapi memiliki kekuatan gaib, sehingga memberikan fungsi sesuai dengan yang diharapkan oleh penggunanya.

\section{Mantra Kata Siti Fatimah Zahaura}

Bismillaahirrahmaaanirrahim

Nur sah, Nur siah

Aku membasuh ceramin Allah

Aku membasuh ceramin Baginda Rasulullah

Oh, Fatimah Zahaura

Sempurnakanlah rupaku

Takaulas, takauning asih

Takaulas, takauning sayang

Tunduk, kasih, sayang Si ... (nama orang) lawan aku

Berakat aku memakai doa Laa Illaha Illallah Muhammadarrasulullah 
Kutipan mantra tersebut mempunyai makna meminta kepada Fatimah putri bungsunya Nabi Muhammad dengan istrinya yang bernama Khadijah untuk menyempurnakan rupanya agar orang yang dituju tersebut menjadi tunduk dan semakin bertambah kasih kepada penggunanya, karena yang mengucapkannya yakin terhadap mantra tersebut dan ditandai dengan doa Laa Illaha Illallah Muhammadarrasulullah.

\section{Mantra Kata Tadung Beranakan}

\section{Bismillaahirrahmaaanirrahim \\ Kulya sinnadri \\ Matahari memancar di mukaku \\ Halilintar membelahkan suaraku \\ Tadung berkokok atas umbun-umbunanku \\ Takaulas, takauning asih \\ Takaulas, takauning sayang \\ Tunduk, kasih, sayang Si ... (nama orang) lawan aku \\ Berakat aku memakai doa Laa Illaha Illallah Muhammadarrasulullah}

Kutipan mantra di atas mempunyai makna bahwa mukanya bercahaya bagaikan matahari dan suaranya merdu, sehingga membuat orang yang dituju tersebut menjadi tunduk, kasihan dan semakin bertambah kasih sayangnya kapada penggunanya, karena si penggunanya yakin terhadap mantra tersebut dan menggunakan doa Laa Illaha Illallah Muhammadarrasulullah.

\section{Mantra Pengunci Diri}

Bismillaahirrahmaaanirrahim

Kunci Allah

Kunci Muhammad

Kunci Baginda Rasulullah

Muhammad menguncikannya

Tertutup, terkunci hati Si ... (nama orang)

Tiada berkehendak kepada orang lain

Selain pada diriku

Berakat Laa Illaha Illallah Muhammadarrasulullah

Kutipan mantra berikut mempunyai makna bahwa meminta pertolongan kepada Allah, Muhammad, dan Rasulullah agar menguncikan hati orang yang dituju sehingga tertutup terkunci hatinya tidak berkehendak kepada orang lain selain kepada Si pengguna mantra tersebut, karena Si penggunanya memiliki keyakinan dan kepercayaan yang kuat terhadap mantra tersebut yakni ditandai dengan doa Laa Illaha Illallah Muhammadarrasulullah. 


\section{Mantra Penunduk Kekasih Hati}

Bismillaahirrahmaaanirrahim

Unduk-unduk piradah patah

Aku berdiri di awan-awan

Inya tunduk tiada berkata

Benar, berani tidak berlawan

Menurut semua perkataanku

Berkat mengatakan doa Laa Illaha Illallah Muhammadarrasulullah

Kutipan mantra yang tergambarkan di atas mempunyai makna tunduk tidak melawan dengan apa yang kita inginkan dan apa yang kita katakan selalu diikutinya. Mantra tersebut diyakini sebagai penunduk kekasih hati oleh Si penggunanya ditandai dengan pemakaian doa Laa Illaha Illallah Muhammadarrasulullah.

\section{Mantra Mandi Pemikat Lawan Jenis}

Bismillaahirrahmaaanirrahim

Allahhumma sholli alla Muhammad

Ampunnya kata Fatimah jua nang menyambutnya

Karim Menimba air di api

Karing tiada ada lagi

Ini benama kambang sekuntum para wali

Inya kepingsan, inya kepati

Singgah memungut si laki-laki

Berakat mengatakan doa Laa Illaha Illallah Muhammadarrasulullah

Kutipan mantra berikut mempunyai makna shalawat yang biasanya digunakan untuk pujian kepada Nabi Muhammad dan Rasulnya, jadi di sana Si penggunanya memuji Nabi Muhammad terlebih dahulu baru meminta permohonan agar apa yang didapatnya sesuai dengan yang diharapkannya, karena yang memiliki rupa yang cantik adalah Fatimah putri bungsu Nabi Muhammad dengan istrinya yang bernama Khadijah, berhati mulia, menjadi incaran para wali yang terkena mantra tersebut, dan mengambilkan hatinya orang yang dituju maksudnya di sana membuat orang yang kita tuju itu menjadi jatuh cinta terpikat kepada Si pengguna mantra, karena yang mengucapkan itu yakin ditandai dengan doa Laa Illaha Illallah Muhammadarrasulullah.

\section{Mantra Pupur Pakasih}

Bismillaahirrahmaaanirrahim

Pupurku Si pupur beras

Ditampi di ujung limbukut

Cahayaku seperti emas

Cahayaku seperti Nabilah Yusuf 
Terkulas, terkening ngasih

Terkening gila-gilalah Si ... (nama orang) kepadaku

Berkat mengatakan doa Laa Illaha Illallah Muhammadarrasulullah

Kutipan mantra tersebut memiliki makna bahwa pupur yang digunakan Si pengguna mantra tersebut dapat membuat orang yang melihatnya tidak bosan untuk memandang rupanya, seperti orang yang melihat emas, melihat rupa Nabi Yusuf yang dipenuhi dengan cahaya, sehingga orang tersebut menjadi terpukau dan tergila-gila kepada Si penggunanya karena didasari keyakinan dan kepercayaan yang dimiliki oleh Si pengguna terhadap mantra yang digunakannya yang ditandai dengan doa Laa Illaha Illallah Muhammadarrasulullah.

\title{
7. Mantra Minyak
}

Bismillaahirrahmaaanirrahim

Burung terbang disengkanya aku

Ayam berkokok disangkanya aku

Angin bertiup disangkanya aku

Orang berjalan disangkanya aku

Tunduk, kasih, sayangnya Si ... (nama orang) lawan aku

Berkat Allah Taalla

Kutipan mantra di atas mempunyai makna apa saja yang ada semua itu dirasanya hanyalah orang yang mengunakan mantra tersebut. Jadi dalam mantra tesebut ibaratkan melihat seekor burung terbang, mendengar suara ayam berkokok, angin berhembus, dan orang berjalan dikiranya iyalah orang yang mengguna-gunainya, karena orang yang dituju tersebut tidak bisa melupakan penggunanya (selalu ingat) dan tunduk kasih kepada penggunanya, itu semua dapat terwujud karena didasari oleh keyakinan Si penggunanya terhadap kekuasaan Allah Ta'ala.

\section{Mantra Mandi Yusuf}

\author{
Bismillaahirrahmaaanirrahim \\ Bapakku Adam \\ Ibuku Siti Hawa \\ Rupaku yusuf \\ Tunduk maras \\ Gila hati Si ... (nama orang) \\ Memandang aku \\ Farduku karena Allah Taalla
}

Kutipan mantranya mempunyai makna bahwa diibaratkan kedua orang tuanya itu adalah Adam dan Hawa, maka rupanya tampan setampan Nabi Yusuf, sehingga membuat semua orang 
atau orang yang dituju melihatnya menjadi tunduk, jatuh cinta dan tergila-gila kepadanya karena keyakinannya terhadap kekuasaan yang dimiliki oleh Allah Ta’ala.

\section{SIMPULAN}

Berdasarkan hasil pembahasan pada bab sebelumnya, maka secara rinci hasil penelitian ini dapat disimpulkan sebagai berikut.

1. Struktur mantra pakasih dalam masyarakat Banjar di Desa Mina Padi Kecamatan Takisung Kabupaten Tanah Laut menggunakan struktur baris pembuka, baris isi, dan baris penutup. Baris pembukanya selalu diawali dengan Bismillaahirrahmaaanirrahim. Baris isinya hampir semua ditandai dengan selalu menyebutkan nama orang yang akan yang akan dituju dan di sana hanya terdapat beberapa mantra yang tidak menyebutkan nama orang yang akan yang akan dituju. Sedangkan baris penutupnya berbeda-beda. Ada yang menggunakan lafadz barakatLaa illahailallah Muhammadarasulullah, ada juga yang menggunakan kalimat berkat Allah Taalla dan kalimat Farduku karena Allah Taalla. Walaupun baris penutup yang digunakan tidak sama, namun struktur mantranya tetap sama.

2. Fungsi mantra pakasih dalam masyarakat Banjar di Desa Mina Padi Kecamatan Takisung Kabupaten Tanah Laut, adalah sebagai pengantar atau alat untuk memperkuat permohonan doa kepada Sang Pencipta yaitu Allah Swt, baik secara langsung maupun melalui perantara roh-roh leluhur dan makhluk halus yang dipercayai memiliki kekuatan gaib yang dapat digunakan untuk menambah kepercayaan diri Si pengguna, menjadi pusat perhatian ditengahorang banyak, memikat orang yang disukai, dan menjadikan orang sayang dan kasih kepada pembaca mantra.

3. Makna mantra pakasih dalam masyarakat Banjar di Desa Mina Padi Kecamatan Takisung Kabupaten Tanah Laut memiliki makna yang berkenaan dengan hubungan manusia dengan Tuhan, berkenaan dengan hubungan manusia dengan roh-roh leluhur, berkenaan dengan hubungan manusia dengan sesamanya, dan berkenaan dengan manusia dengan dirinya sendiri. Makna yang terkandung dalam mantra-mantra tersebut harus diyakini dan dipercayai oleh orang yang membacakannya agar setiap doa yang dipanjatkan dapat terkabul. 


\section{SARAN}

Berdasarkan simpulan di atas, maka dapat dikemukakan saran-saran sebagai berikut.

1. Bagi pembaca dan peneliti sastra, disarankan untuk mengetahui segala jenis sastra, termasuk sastra lisan genre lama yang berjenis mantra.

2. Bagi Penikmat Sastra, diharapkan agar penelitian ini dapat dijadikan sebagai bahan bacaan yang bermanfaat dalam mengapresiasi karya sastra, khususnya sastra lisan genre lama yang berupa mantra.

3. Peneliti selanjutnya dapat memperdalam penelitian ini dengan mengadakan penelitian lanjutan mengenai sastra lisan genre lama yang berupa mantra. Hal ini bertujuan agar dapat menambah pemahaman terhadap karya sastra.

\section{DAFTAR RUJUKAN}

AR, Syamsuddin dan Vismaia S. Damaianti. 2015. Metode Penelitian Pendidikan Bahasa. Bandung: Rosda.

Astika, I Made dan I Nyoman Yasa. 2014. Sastra Lisan Teori dan Penerapannya. Yogyakarta: Graha Ilmu.

Endraswara, Suwardi. 2013. Metodologi Penelitian Antropologi Sastra. Yogyakarta: Ombak.

Hapip, Abdul Djebar. 2008. Tata Bahasa Banjar. Banjarbaru: CV Aditama.

Laelasari, dan Nurlailah. 2008. Kamus Istilah Sastra. Bandung: Nuansa Aulia.

Rafiek, Muhammad. 2012. Teori Sastra: Kajian Teori dan Praktik. Bandung: PT Refika Aditama.

Ratna, Nyoman Kutha. 2011. Antropologi Sastra: Peran Unsur-Unsur Kebudayaan dalam Proses Kreatif. Yogyakarta:Pustaka Pelajar.

Ratna, Nyoman Kutha. 2015. Teori, Metode, dan Teknik Penelitian Sastra. Yogyakarta: Pustaka Pelajar.

Sugiarto, Eko.2015. Mengenal Sastra Lama: Jenis, Definisi, Ciri, Sejarah, dan Contoh. Yogyakarta: Andi.

Sulistyowati, Endang dan Tajuddin Noor Ganie. 2015. Sastra Banjar Genre Lama Bercorak Puisi. Banjarmasin: Tuas Media.

Sulistyowati, Endang dan Tarman Effendi Tarsyad. 2015. Kajian Puisi. Banjarbaru: Scripta Cendekia. 